\title{
Corticosterone alters insulin signaling in chicken muscle and liver at different steps
}

\author{
J Dupont, M Derouet, J Simon and M Taouis \\ Institut National de la Recherche Agronomique, Station de Recherches Avicoles, Laboratoire d'Endocrinologie Moléculaire et Cellulaire du Métabolisme, \\ Centre de Tours, Nouzilly 37380, France \\ (Requests for offprints should be addressed to M Taouis)
}

\begin{abstract}
Chronic treatment with corticosterone evokes insulin resistance in chickens, a species which is already resistant to insulin compared with mammals. The in vivo effects of corticosterone on insulin signaling were investigated in chicken liver and thigh muscle in two nutritional states: basal (overnight fasted) and stimulated (30 min refeeding). Corticosterone significantly decreased specific insulin binding in liver and the amount of insulin receptor substrate-1 (IRS-1) and p85 (regulatory subunit of phosphatidylinositol (PI) 3'-kinase) in both tissues. Insulin receptor (IR) and IRS-1 mRNAs generally varied accordingly. Src homology and collagen protein (Shc) and messenger were not altered. In liver, in the basal state, the tyrosine phosphorylation of IR, IRS-1 and Shc, and the IR-associated PI 3'-kinase activity were largely decreased
\end{abstract}

by corticosterone. Following refeeding the cascade was activated in control but totally inhibited in treated chickens. In muscle, as previously observed, IR and IRS-1 phosphorylation and PI 3'-kinase were not stimulated by refeeding in controls. Only the phosphorylation of Shc was increased. On this background, corticosterone decreased the basal PI 3'-kinase activity and prevented the phosphorylation of Shc in response to refeeding. In conclusion, corticosterone largely impaired insulin signaling in liver and to some extent in muscle. This should contribute to the large impairment of growth. In addition, the present studies further emphasize the peculiarities of insulin signaling in chicken muscle, which needs further investigation.

Journal of Endocrinology (1999) 162, 67-76

\section{Introduction}

Glucocorticoids have various metabolic effects. In liver, they increase glucose production (Amatruda et al. 1985), whereas, in adipose tissue and muscle, they antagonize insulin-mediated uptake and utilization of glucose (Baxter \& Forshman 1972, Olefsky 1975). They also promote lipolysis by activating the cAMP-dependent hormonesensitive lipase (Cahill 1971), although in vivo in the long term, fattening is observed. In skeletal muscle proteolytic activity is largely enhanced (Cahill 1971, Exton et al. 1976). These metabolic alterations have been attributed to a direct action of glucocorticoids or/and to an insulin resistant state via the impairment of insulin signaling (Saad et al. 1993). Insulin action is mediated through a cascade of events initiated by its binding to a transmembrane receptor, followed by an autophosphorylation and the activation of an intrinsic tyrosine kinase which phosphorylates cellular substrates. Among these substrates, members of the insulin receptor substrate (IRS) family (four at the moment) are considered as major substrates for insulin receptors (IR), which are docking proteins without enzymatic activity (Sun et al. 1991, Patti et al. 1995, Lavan et al. 1997a,b). Shc (Src homology and collagen protein), which is involved in the mitogenic signaling of a variety of tyrosine kinase growth-promoting receptors, such as those for platelet-derived growth factor, epidermal growth factor and nerve growth factor, through the ras/raf cascade, is also considered as an IRS (Pelicci et al. 1992, Sasaoka et al. 1994, Migliaccio et al. 1997).

Various proteins such as phosphatidylinositol (PI) 3'kinase, SH2-containing phosphotyrosine phosphatase, growth factor receptor binding protein Grb2, protooncogene Nck, and cytosolic tyrosine kinase Fyn, promote the metabolic or mitogenic effects of insulin by associating with tyrosine phosphorylated IRS-1 (Case et al. 1994, Myers et al. 1994, White \& Kahn 1994, Sanchez-Margelet et al. 1995, Saltiel 1996). Therefore, glucocorticoidinduced insulin resistance may result from an alteration at the level of one or several molecules involved in the cascade.

In the chicken, an insulin-resistant species, exogenous corticosterone (the major glucocorticoid in this species) impairs muscle growth, induces excessive fattening and further exaggerates insulin resistance. In liver, corticosterone alters IR number and tyrosine kinase activity of lectin-purified receptors (Taouis et al. 1993). In contrast, the tyrosine kinase activity of muscle receptors is not 
altered by exogenous corticosterone. Recently, chicken IRS-1 gene has been cloned (Taouis et al. 1996) and IRS-1 protein has been characterized in liver and muscle (Dupont et al. 1998a). IRS-1 tyrosine phosphorylation is dependent upon the nutritional state in the liver but surprisingly not in muscle. Chicken Shc has been also partially cloned and characterized in chicken tissues (Dupont et al. 1998b). In liver and muscle, Shc associates with IR and its tyrosine phosphorylation is dependent upon the nutritional state in both tissues. Shc also associates with a PI 3 '-kinase activity in both liver and muscle suggesting a metabolic role under insulin control for Shc in this species. Finally, a multimeric complex involving IR, IRS-1, Shc (mainly the $52 \mathrm{kDa}$ isoform) and p85 (regulatory subunit of PI $3^{\prime}$-kinase) and a PI 3 '-kinase activity is present in chicken tissues, at least in liver. So far the presence of this complex has not yet been demonstrated in mammals.

In order to identify the steps accounting for the corticosterone-induced insulin resistance in the chicken, the effect of daily injections of corticosterone on IR, IRS-1 and She tyrosine phosphorylation as well as IRassociated PI 3'-kinase activity was examined in liver and muscle. Two nutritional states were considered: basal state (overnight fasting) and stimulated state (30 min refeeding).

\section{Materials and Methods}

\section{Chemicals}

Monoiodinated porcine ${ }^{125}$ I-labeled insulin was purchased from Amersham France (Les Ulis, France) and $\left[\gamma-{ }^{33} \mathrm{P}\right]$ ATP were obtained from Isotopchim (Peyruis, France). Monocomponent porcine insulin was obtained from Novo Industrie Pharmaceutique (Paris, France). BSA (fraction V RIA grade), phenylmethylsulfonylfluoride, leupeptin, aprotinin, protein A-agarose, PI and corticosterone were purchased from Sigma Chemical Co. (St Louis, MO, USA). Triton X-100, SDS and nitrocellulose membrane were obtained from Bio-Rad Laboratories (Richmond, CA, USA) and pre-made polyacrylamide solution protogel was from Prolabo (National Diagnostic, Gredignon, France). Silica thin layer chromatography (TLC) plates were obtained from Carlo Erba (Val de Reuil, France). The Quick Prep total RNA extraction kit, deoxy-nucleotide triphosphate dNTP, Taq polymerase, avian myeloblastosis virus reverse transcriptase and RNase ribonuclease inhibitor were purchased from Pharmacia (Bois d'Acy, France). Nylon membranes (Hybond $\mathrm{N}+$ ) were from Amersham. Random hexamer primers were purchased from Promega (Charbonnieres, France). Primers used for reverse transcription PCR (RT-PCR) were provided by Genosys (Cambridge, UK) and by Gibco BRL (Life Technologies, Cergy Pontoise, France). Antibodies to Shc ( $\alpha$ Shc), IR ( $\alpha$ IR) and phosphotyrosine ( $\alpha$ PY20) were from Transduction Laboratories (Ozyme, France). Antibodies to p85 (ap85) were obtained from UBI (Lake Placid, NY, USA). Antibodies to IRS-1 ( $\alpha$ IRS-1) were purchased from UBI and Transduction Laboratories. Dithiothreitol, horseradish peroxidase conjugated with specific secondary antibodies and ECL (enhanced chemiluminescence) reagents were from Pierce (Ozyme, France).

\section{Animals and experimental procedures}

Male broiler chickens (Shaver, Sicamen, France) were housed in a conventional floor pen. After 4 weeks, 40 chickens were placed in individual cages, fed freely with a balanced diet $(3100 \mathrm{kcal} / \mathrm{kg}$ metabolizable energy and $22 \%$ protein) and exposed to a daily $14 \mathrm{~h}$ light period. Corticosterone was dissolved in benzyl alcohol at $37^{\circ} \mathrm{C}$ and diluted in corn oil to a final concentration of $10 \%$ benzyl alcohol. At 5 weeks of age, chickens were separated into two groups of 20 animals each and treated with corticosterone $(6 \mathrm{mg} / \mathrm{kg}$ per day) or placebo (1/10 benzyl alcohol in corn oil). After 1 week of treatment, insulin sensitivity was measured in ten overnight-fasted chickens (control and corticosterone-treated). They received an i.m. injection of saline or $40 \mu \mathrm{g}$ insulin $/ \mathrm{kg}$ and after $90 \mathrm{~min}$ blood samples were taken from a wing vein. The other chickens (control and corticosterone-treated animals) were separated into two groups and submitted to two nutritional states: fasted overnight, and refed for 30 min after the overnight fast. Following blood sampling, chickens were killed by cervical dislocation. Tissues (liver and thigh muscles) were quickly removed, frozen in liquid nitrogen, ground into powder and stored at $-80{ }^{\circ} \mathrm{C}$ until used.

\section{Determination of plasma glucose and insulin levels}

Plasma glucose levels were measured by the glucose oxidase method (Glucose Beckman Analyser 2, Beckman, Palo Alto, CA, USA) and plasma insulin levels by an RIA with a guinea pig anti-porcine insulin antibody (Ab 27-6, generously provided by Dr G Rosselin, Hopital Saint-Antoine, Paris) using chicken insulin as the standard.

\section{Binding of insulin to liver membranes}

Liver membranes were prepared as previously described (Dupont et al. 1998a). Aliquots of $50 \mu \mathrm{l}$ crude membrane $(0.4 \mathrm{mg} / \mathrm{ml})$ were incubated overnight at $4{ }^{\circ} \mathrm{C}$ with ${ }^{125} \mathrm{I}-$ insulin at $0.1 \mathrm{ng} / \mathrm{ml}$ in the absence or presence of increasing concentrations of unlabeled monocomponent porcine insulin $(4-40000 \mathrm{ng} / \mathrm{ml})$. The assay was terminated by centrifugation of the tubes at $12000 \mathrm{~g}$ for $3 \mathrm{~min}$ at $4{ }^{\circ} \mathrm{C}$. The pellets were washed with $0 \cdot 2 \mathrm{ml}$ of chilled sucrose $(0 \cdot 25 \mathrm{M})$ and radioactivity in them counted.

\section{Immunoblotting and immunoprecipitation procedures}

Liver and muscle protein lysates were prepared as previously described (Taouis et al. 1994, Dupont et al. 1998a). 
Protein concentration of supernatants was determined using the Bradford dye binding assay kit (Bio-Rad). After normalization for protein concentration $(5 \mathrm{mg})$ the supernatants were immunoprecipitated with different antibodies: $\alpha$ PY20 $(1 / 200)$ and $\alpha$ IR $(1 / 100)$ at $4{ }^{\circ} \mathrm{C}$ during $16 \mathrm{~h}$. The immune complexes were precipitated with protein A-agarose for $1 \mathrm{~h}$ at $4{ }^{\circ} \mathrm{C}$ as previously described (Taouis et al. 1994, Dupont et al. 1998a). After two sequential washes using diluted buffer $(1 / 2)$, the resulting pellets were boiled for $4 \mathrm{~min}$ in reducing Laemmli buffer containing $80 \mathrm{mM}$ dithiothreitol. Proteins were resolved by SDS-PAGE and transferred to nitrocellulose membranes. Blots were blocked and probed with $\alpha$ IR, $\alpha$ IRS-1 or $\alpha$ Shc at $1 / 1000$ dilution. After extensive washings, immune complexes were detected with horseradish peroxidase conjugated with specific secondary antiserum followed by an ECL reaction. Band densities were estimated by using the NIH Image software (Bethesda, MD, USA).

\section{PI 3'-kinase assay}

PI 3'-kinase activity was determined as previously described (Levy-Toledano et al. 1994, Taouis et al. 1994). Briefly, the liver and muscle homogenates were immunoprecipitated using $\alpha$ IR. PI 3 '-kinase activity was determined in immunoprecipitates in the presence of PI (as substrate) and labeled ATP. Following migration onto TLC plates, the level of PI phosphorylation was measured using Storm Apparatus (Molecular Dynamics, Bondoufle, France).

\section{IR, IRS-1, Shc and $p 85 m R N A$ expression}

Following RNA extraction from liver and muscle of fasted control or corticosterone-treated chickens, total RNAs were subjected to RT-PCR as previously described (Taouis et al. 1996). RT reactions were primed with random hexamers and PCR was carried out in the presence of five sets of primers flanking: a $490 \mathrm{bp}$ fragment of IRS-1 (sense: 5' GCCCGGCCCACGAGGCTG 3' (2630-2648) and antisense: 3' GTACGCTTGTCCGT AACG 5' (3120-3102)), a 383 bp fragment of IR (sense: 5' TTTGGGATGGTTTATGAGGG $3^{\prime}$ and antisense: $3^{\prime}$ GCCAGGTCTCTGTGAACAAA 5'), a 344 bp fragment of p85 (sense: 5' AACCTTCAACTCTGTGGTTG 3' (1762-1781) and antisense: 3' TCGCCATGTCGTT TCTTATG 5' (2098-2079)), a 594 bp fragment of Shc (sense: $5^{\prime}$ CGGGAGCTTTGTCAATAAGCC $3^{\prime}$ and antisense: 5' GAGCCATCAAAGCCAGCCATC $3^{\prime}$ ) and, as control, a $515 \mathrm{bp}$ fragment of $18 \mathrm{~S}$ RNA (sense: 5' CTGCCCTATCAACTTTCG 3' and antisense: 3' GGCGTCGATCCTTATTAC 5').

\section{Southern blotting}

Following RT-PCR and electrophoresis, amplified products were transferred onto nylon membranes. The blots
Table 1 Effect of corticosterone treatment on body weight, food intake and liver weight after 1 week of treatment. Chickens were overnight fasted (16 h). Means \pm S.E.M., $n=5$

\begin{tabular}{lrlc} 
& \multicolumn{1}{c}{ Control } & & Corticosterone \\
\cline { 2 - 2 } Body weight $(\mathrm{g})$ & $2471 \cdot 0 \pm 32 \cdot 1$ & & $1857 \cdot 7 \pm 33 \cdot 1^{* * *}$ \\
Food intake $(\mathrm{g})$ & $1258 \cdot 2 \pm 32 \cdot 4$ & & $1328 \cdot 0 \pm 55 \cdot 2$ \\
Liver weight $(\mathrm{g})$ & $42 \cdot 63 \pm 1 \cdot 61$ & & $74 \cdot 07 \pm 1 \cdot 75^{* * *}$ \\
Liver weight (\% body weight) & $1 \cdot 72 \pm 0 \cdot 06$ & & $4 \cdot 00 \pm 0 \cdot 11^{* * *}$ \\
\cline { 2 - 3 } & & \\
\cline { 2 - 3 }
\end{tabular}

${ }^{* * *} P<0 \cdot 001$

were hybridized using $6 \times 10^{6}$ c.p.m. of ${ }^{33} \mathrm{P}$-labeled primers using T4 polynucleotide kinase. Prehybridization was carried out in a buffer containing $50 \%(\mathrm{v} / \mathrm{v})$ formamide, $5 \times \mathrm{SSC}(1 \times \mathrm{SSC}=0 \cdot 15 \mathrm{M}$ sodium chloride, $0 \cdot 015$ M sodium citrate), $50 \% 10 \times$ Denhardt's solution, $1 \%$ SDS and $50 \mathrm{mM}$ Tris- $\mathrm{HCl} \mathrm{pH} 7.5$ for $4 \mathrm{~h}$ at $55^{\circ} \mathrm{C}$. Hybridization was performed in the same buffer at $55^{\circ} \mathrm{C}$ for $16 \mathrm{~h}$. Southern blots were revealed by autoradiography and quantified using Storm Apparatus (Molecular Dynamics).

\section{Statistical analysis}

For statistical comparisons between control and corticosterone-treated chickens, Student's $t$-test was used.

\section{Results}

\section{Characteristics of corticosterone-treated chickens}

As previously observed (Taouis et al. 1996), overnightfasted chickens treated with $6 \mathrm{mg}$ corticosterone $/ \mathrm{kg}$ per day for 1 week showed significant $(P<0 \cdot 001)$ reduction in body weight and a striking augmentation in liver weight (Table 1). Food intake was not affected by corticosterone treatment (Table 1).

\section{Effect of corticosterone treatment on glycemia, insulinemia and} insulin sensitivity

Glycemia and insulinemia were measured in control and corticosterone-treated chickens in two nutritional states (fasted for $16 \mathrm{~h}$ and refed for $30 \mathrm{~min}$ after fasting). In the fasted state, corticosterone induced a marked $(P<0 \cdot 05)$ hyperglycemia associated with a slight hyperinsulinemia as compared with control chickens (Table 2). In the refed state, in both control and treated chickens, plasma insulin $(P<0 \cdot 05)$ and glucose levels increased above the fasted state levels and were significantly higher $(P<0 \cdot 05)$ in corticosterone-treated chickens (Table 2 ). Ninety minutes following injection of saline or $40 \mu \mathrm{g}$ insulin $/ \mathrm{kg}$, plasma glucose levels were $2 \cdot 00 \pm 0.08$ (S.E.M.) and $0.65 \pm$ $0 \cdot 10 \mathrm{~g} / 1$ in control chickens $(P<0 \cdot 05)$ and $2 \cdot 42 \pm 0 \cdot 15$ and 
Table 2 Effect of corticosterone on plasma glucose and insulin levels after 1 week of treatment in fasted (overnight) and refed $(30 \mathrm{~min})$ chickens. Values are means \pm S.E.M. of five animals of each group

\begin{tabular}{|c|c|c|c|c|}
\hline & \multicolumn{2}{|l|}{ Control } & \multicolumn{2}{|c|}{ Corticosterone } \\
\hline & Fasted & Refed & Fasted & Refed \\
\hline Insulin $(\mu \mathrm{g} / \mathrm{l})$ & $0 \cdot 30 \pm 0 \cdot 08$ & $3 \cdot 60 \pm 0 \cdot 84$ & $0.62 \pm 0.15$ & $7 \cdot 75 \pm 3 \cdot 14$ \\
\hline Glucose (g/l) & $1.99 \pm 0.04$ & $2 \cdot 48 \pm 0 \cdot 15$ & $3 \cdot 12 \pm 0 \cdot 45^{*}$ & $5 \cdot 41 \pm 0 \cdot 85^{\dagger}$ \\
\hline
\end{tabular}

$1 \cdot 73 \pm 0 \cdot 30 \mathrm{~g} / 1$ in corticosterone-treated chickens (not significant) respectively. Thus, exogenous insulin was less efficient in treated animals.

IR number in liver and muscle of corticosterone-treated chickens Specific insulin binding was measured on liver membranes using monoiodinated insulin and its density was determined by Western blotting using a specific $\alpha$ IR. In liver, corticosterone significantly $(P<0 \cdot 05)$ reduced specific insulin binding as estimated using both techniques (Figs 1 and 2), without altering IR affinity (Fig. 1). In muscle, IR number cannot be estimated using membrane binding due to the high proportion of non-specific binding of labeled insulin (Adamo et al. 1987). In Western blot analysis using $\alpha \mathrm{IR}$ we showed that corticosterone slightly

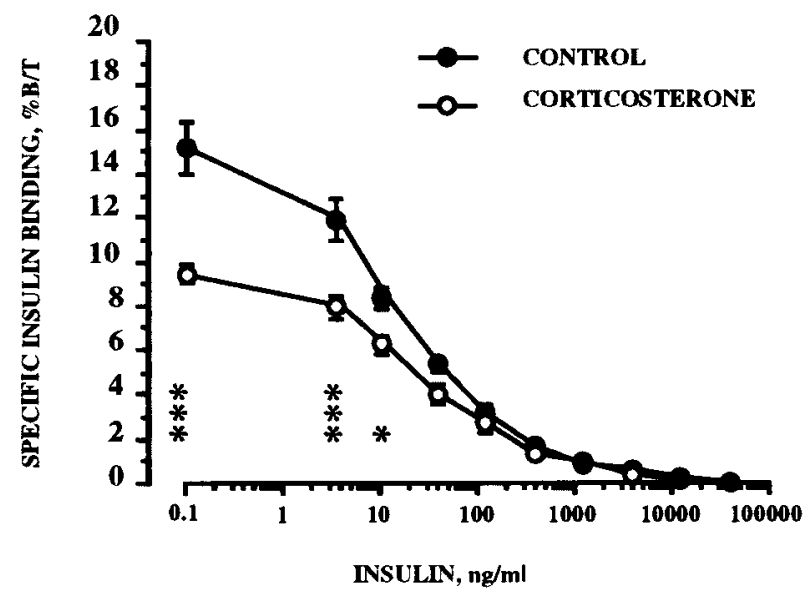

Figure 1 Competitive inhibition of ${ }^{125}$ I-labeled porcine insulin binding to liver membranes of control and corticosterone-treated chickens. Liver membranes were prepared from fasted control and treated chickens. Crude membranes were incubated in the presence of labeled insulin $(0.1 \mathrm{ng} / \mathrm{ml})$ for $16 \mathrm{~h}$ at $4{ }^{\circ} \mathrm{C}$ in the absence or presence of increasing concentrations of unlabeled porcine insulin. The percentage of maximal specific binding of ${ }^{125} \mathrm{I}$-insulin was determined and plotted against different unlabeled insulin concentrations. Data are means \pm S.E.M., $n=4,{ }^{*} P<0 \cdot 05$, $* * * P<0 \cdot 001$. reduced muscle IR density (Fig. 2) (30.0 $\pm 5 \cdot 0$ for control and $21 \cdot 3 \pm 3 \cdot 0$ arbitrary units for treated chickens as determined by densitometry using $\mathrm{NIH}$ Image software).

\section{Effect of corticosterone on IRS-1, She and p 85 protein levels}

To determine the effect of corticosterone on IRS-1, Shc and p85 protein levels, liver and muscle lysates from fasted control and treated chickens were subjected to Western blotting and nitrocellulose membranes were blotted with $\alpha$ IRS-1, $\alpha$ Shc or $\alpha p 85$. Band densities were quantified using the NIH Image software. In liver (Fig. 3A), IRS-1 and 85 protein amounts were decreased by $46 \cdot 0 \pm 12 \cdot 0$ and $78.9 \pm 4 \cdot 8 \%(P<0 \cdot 05)$ respectively, in corticosteronetreated chickens as compared with control chickens. In

\section{IP : $\alpha$ IR \\ Blot : $\alpha$ IR}

\section{LIVER}

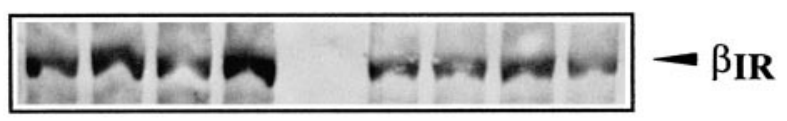

\section{MUSCLE}

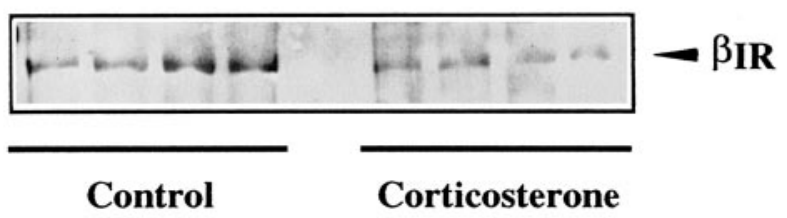

Figure 2 IR protein levels in liver and muscle of fasted control and corticosterone-treated chickens. Liver and muscle samples from fasted control and treated chickens $(n=4)$ were solubilized and proteins immunoprecipitated using $\alpha$ IR. Immunoprecipitates were analyzed on $10 \%$ SDS-PAGE followed by electrotransfer. Blots were probed with $\alpha \mathrm{IR}$ and bands corresponding to IR $\beta$ (95 kDa) were detected by ECL. 
muscle (Fig. 3B), the same result was observed, IRS-1 and p85 protein levels were decreased by $52.5 \pm 9 \cdot 0$ and $51 \cdot 1 \pm 3 \cdot 3 \% \quad(P<0 \cdot 05)$ respectively, in corticosterone-

\section{A : LIVER}

\section{Blot : $\alpha$ IRS-1}

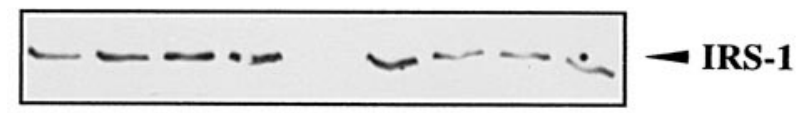

\section{Blot : $\alpha$ p85}

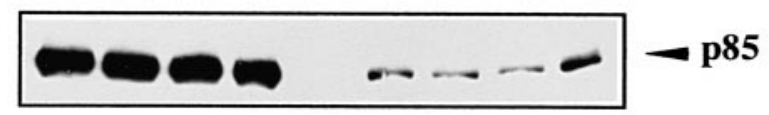

\section{Blot : $\alpha$ Shc}

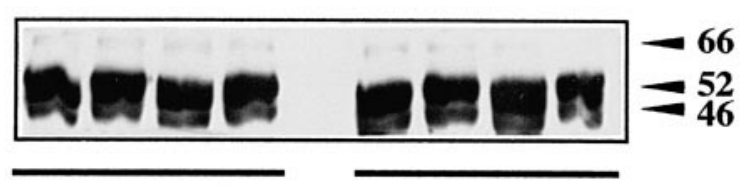

Control

Corticosterone

\section{B : MUSCLE}

Blot : $\alpha$ IRS-1

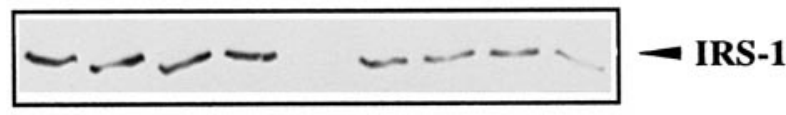

Blot : $\alpha p 85$

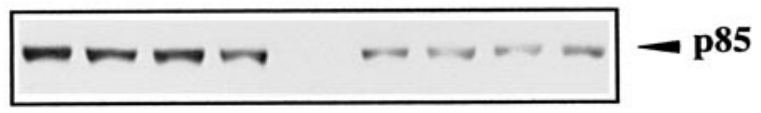

Blot : $\alpha$ Shc

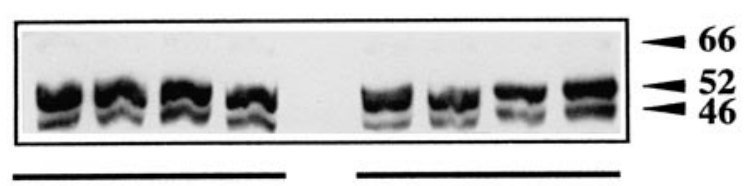

\section{Control Corticosterone}

Figure 3 IRS-1, p85 and Shc protein levels in liver (A) and muscle (B) of fasted control and corticosterone-treated chickens. Samples were solubilized as described in Materials and Methods. Lysates containing $125 \mu \mathrm{g}$ protein were resolved on SDS-PAGE (10\%) and electrotransferred to nitrocellulose membranes. Blots were successively probed with $\alpha$ IRS- 1 , $\alpha \mathrm{p} 85$ and $\alpha$ Shc and bands corresponding to IRS-1 (185 kDa), p85 (85 kDa) and Shc (66, 52, $46 \mathrm{kDa})$ were revealed by ECL. $n=4$ animals per treatment. treated chickens. In both tissues, corticosterone did not alter Shc protein levels (Fig. 3A and B).

\section{Effect of corticosterone on IR, IRS-1 and Shc mRNA} expression

To determine whether the changes in protein amounts noticed after corticosterone treatment were the consequence of RNA messenger alterations, IR, IRS-1, Shc and p85 mRNA expressions were measured. Total RNA from liver or muscle of control and treated chickens was extracted and subjected to RT-PCR, and Southern blotting was performed using the respective specific primers and probes, as described in Materials and Methods. As control, 18S RNA expression was determined in the same conditions. For each individual samples, IR, IRS-1, Shc and p85 mRNA were expressed as a ratio over 18S RNA (as percentage). In liver (Table 3), corticosterone significantly $(P<0 \cdot 05)$ reduced IR and p $85 \mathrm{mRNA}$ levels by $28 \pm 4$ and $30 \pm 3 \%$ respectively. IRS -1 and Shc mRNA levels were not altered by corticosterone treatment. In muscle (Table 3), corticosterone decreased $(P<0 \cdot 05)$ IRS-1 and p85 mRNA levels by $34 \cdot 9 \pm 5 \cdot 0$ and $18 \cdot 0 \pm 3 \cdot 0 \%$ respectively. In muscle as in liver, Shc mRNA expression was not altered by corticosterone treatment.

Effect of corticosterone treatment on IR, IRS-1 and Shc tyrosine phosphorylation

The impact of corticosterone on insulin signal transduction was studied by determining its effect on tyrosine phosphorylation of IR, IRS-1 and She in the two nutritional states (fasted and refed states). Liver and muscle lysates were immunoprecipitated with $\alpha$ PY20 and blotted with $\alpha$ IR, $\alpha$ IRS- 1 or $\alpha$ Shc. In liver (Fig. $4 \mathrm{~A}-\mathrm{C}$ ), in the basal (overnight-fasted) state, corticosterone treatment significantly decreased the tyrosine phosphorylation of IR, IRS-1 and Shc by $44 \pm 6,39 \pm 8$ and $38 \pm 5 \%$ respectively ( $P<0.05$ for each protein). In control chickens, liver IR, IRS-1 and Shc tyrosine phosphorylation was significantly increased by refeeding as compared with the fasted state, most likely in response to the increase of plasma insulin levels (see Table 2). Corticosterone treatment completely abolished the increase in tyrosine phosphorylation of liver IR, IRS-1 and Shc associated with the refed state. In muscle (Fig. 5A and B), in the basal state, the tyrosine phosphorylation of IR, IRS-1 and She was similar in control and corticosterone-treated chickens. Refeeding did not alter the phosphorylation of IR or IRS-1 in control chickens, as previously described (Dupont et al. 1998a), as well as in corticosterone-treated chickens. In contrast, in control chicken muscle, Shc tyrosine phosphorylation was significantly $(P<0 \cdot 05)$ increased by refeeding as compared with the fasted state as previously described (Dupont et al. 1998b); this effect was not detected in corticosterone-treated chickens (Fig. 5C). 
Table 3 Expression of IR, IRS-1, p85 and Shc in liver and muscle of control and corticosterone-treated chickens. Total RNA was extracted and subjected to RT-PCR and Southern blotting as in Materials and Methods. Incorporated radoactivity was measured using Storm Apparatus and results were expressed as a ratio over 18S RNA (\%). Values are means \pm S.E.M. of four chickens of each group

\begin{tabular}{|c|c|c|c|c|}
\hline \multicolumn{3}{|c|}{ Liver } & \multicolumn{2}{|l|}{ Muscle } \\
\hline & Control & Corticosterone & Control & Corticosterone \\
\hline IR & $54 \cdot 2 \pm 5 \cdot 0$ & $39 \cdot 2 \pm 3 \cdot 0^{*}$ & $55 \cdot 4 \pm 2 \cdot 0$ & $53 \cdot 2 \pm 3 \cdot 0$ \\
\hline IRS-1 & $14 \cdot 4 \pm 1 \cdot 1$ & $11 \cdot 9 \pm 0.5$ & $17 \cdot 6 \pm 1 \cdot 6$ & $11 \cdot 5 \pm 0 \cdot 2^{*}$ \\
\hline Shc & $86 \cdot 8 \pm 10 \cdot 0$ & $76 \cdot 2 \pm 5 \cdot 6$ & $72 \cdot 2 \pm 6 \cdot 0$ & $73 \cdot 5 \pm 12 \cdot 2$ \\
\hline p85 & $11 \cdot 2 \pm 0 \cdot 9$ & $7 \cdot 5 \pm 0 \cdot 3^{*}$ & $34 \cdot 7 \pm 1 \cdot 6$ & $25 \cdot 7 \pm 1 \cdot 2^{*}$ \\
\hline
\end{tabular}

${ }^{*} P<0 \cdot 05$

\section{Corticosterone treatment altered PI $3^{\prime}$-kinase activity associated with IR}

To determine the impact of changes in IR, IRS-1 and Shc tyrosine phosphorylation on a further downstream event, the PI 3'-kinase activity associated with IR was measured in liver and muscle of control and corticosterone-treated chickens in the two nutritional states. Liver and muscle lysates were immunoprecipitated with $\alpha \mathrm{IR}$ and PI $3^{\prime}-$ kinase activity measured in the resulting precipitates as described in Materials and Methods. The basal (fasted state) liver PI 3'-kinase activity (Fig. 6A) was reduced by $33 \pm 7 \%(P<0 \cdot 05)$ in corticosterone-treated chickens. The liver PI 3'-kinase activity significantly $(P<0.05)$ increased in the refed state as compared with the fasted state in control chickens but this effect was abolished in corticosterone-treated chickens. In muscle (Fig. 6B), basal PI 3 '-kinase activity was also significantly $(P<0 \cdot 05)$ reduced by corticosterone treatment and this at a higher extent than in liver $(71 \pm 9 \%$ in corticosterone-treated chickens as compared with controls). Both in control and corticosterone-treated chickens, muscle PI 3'-kinase activity was not stimulated by refeeding.

\section{Discussion}

Corticosterone treatment impaired growth and evoked insulin resistance as evidenced by the presence of hyperglycemia and hyperinsulinemia, both in the fasting $(16 \mathrm{~h})$ or refed $(30 \mathrm{~min})$ state and by the decrease in the potency of exogenous insulin to exert its hypoglycemic effect, as previously observed (Taouis et al. 1993). The impact of corticosterone treatment on the early steps of insulin signaling (i.e. IR, IRS-1, Shc phosphorylation and PI $3^{\prime}$-kinase activity) has been examined in the two nutritional states. Corticosterone reduced the liver membrane IR number, which is probably the consequence of a down-regulation induced by the enhanced insulin levels found in treated chickens. In muscle, IR (seen through Western blot) was not clearly altered. In rat, dexametha- sone does not alter the number of liver or muscle IRs despite an increase in plasma insulin levels (Saad et al. 1993). The origin of the discrepancy between these two species for liver IR number is unknown. We have also investigated the effect of corticosterone on the protein amounts of molecules involved in the early steps of IR cascade, such as IRS-1, Shc and p85. Corticosterone treatment decreased IRS-1 levels in chicken liver and muscle. In rat muscle, glucocorticoids have similar effects (Giorgino et al. 1993, Saad et al. 1993), whereas, in liver, dexamethasone significantly increased IRS-1 levels indicating that this treatment may antagonize the effect of insulin (Folli et al. 1996). Corticosterone also decreased p85 levels in liver and muscle, whereas no changes were noticed for Shc protein levels in both tissues. These findings corroborate previous results showing that hypoor hyperinsulinemic states induced by fasting or refeeding did not alter Shc levels (protein or mRNA) in liver and muscle (Dupont et al. 1998b).

Corticosterone treatment reduced basal (fasted state) IR tyrosine phosphorylation in liver and completely abolished the activating effect of refeeding. In muscle, corticosterone treatment, as for the control, did not alter IR tyrosine phosphorylation in either the fasted or refed state.

In liver, in the basal state (fasted), the amount of tyrosine phosphorylated IRS-1 and Shc was largely decreased by corticosterone. More likely, the decrease in tyrosine phosphorylation of the two substrates, IRS-1 and Shc, is subsequent to the reduced number and phosphorylation of IR despite an increase in insulin plasma levels. The modifications presently observed indicate the presence of an insulin resistance in liver. This is further demonstrated by the response to the refeeding. In control chickens, the tyrosine phosphorylation of IRS-1 and Shc was largely stimulated. In contrast, in treated chickens such stimulation was totally abolished. These alterations, added to the decrease in receptor number and phosphorylation, should lead to liver insulin resistance. In the rat, the phosphorylation of Shc has not been examined in similar conditions, at least to our knowledge. 
A

IP : $\alpha$ PY20

Blot : $\alpha$ IR

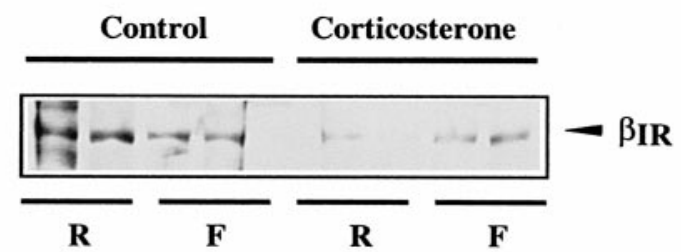

B

IP : $\alpha$ PY20

Blot : $\alpha$ IRS-1
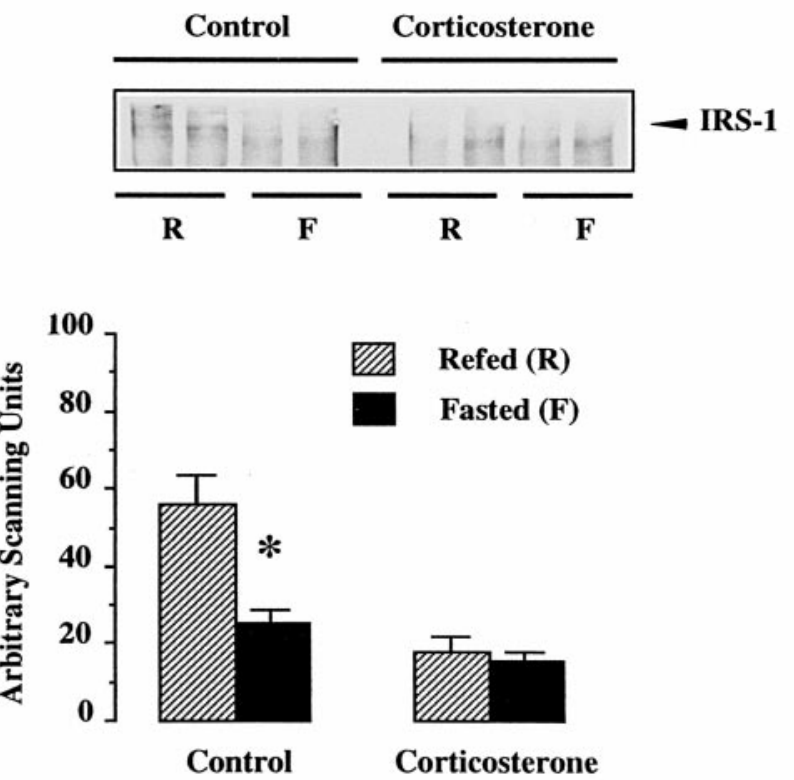

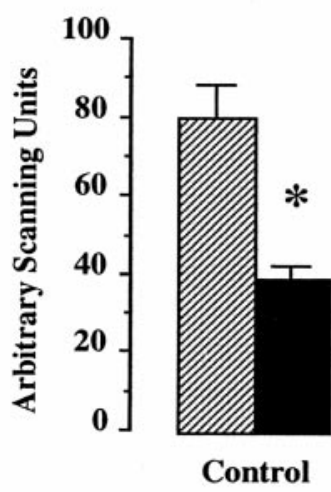

UTA Refed (R)

Fasted (F)

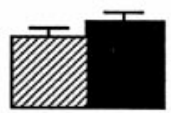

Corticosterone

C

IP : $\alpha$ PY20

Blot : $\alpha$ Shc
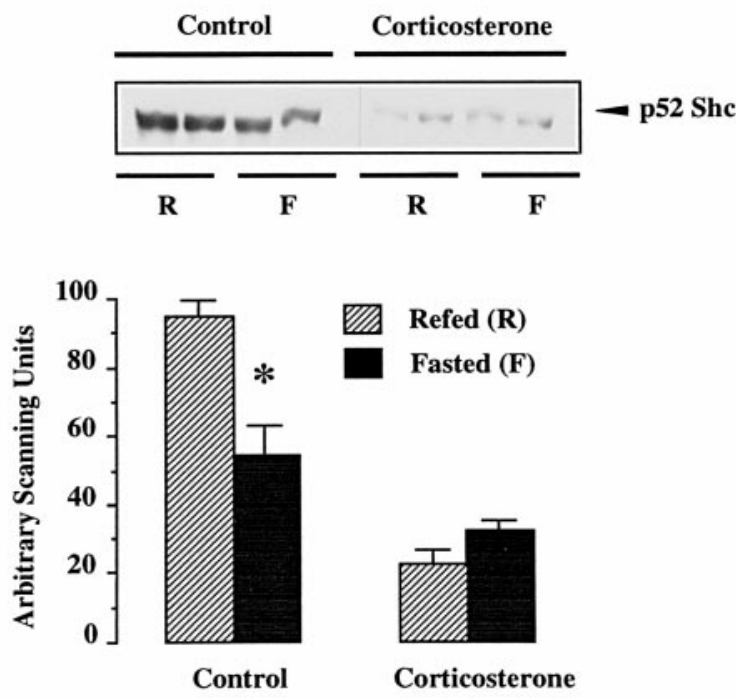

Figure 4 IR $\beta$-subunit (A), IRS-1 (B) and Shc (C) tyrosine phosphorylation in liver of control and corticosterone-treated chickens in fasted and refed states. Solubilized proteins $(5 \mathrm{mg}$ ) were immunoprecipitated using $\alpha$ PY20. Immunoprecipitates were resolved on $10 \%$ SDS-PAGE followed by electroblotting. Blots were successively probed with $\alpha \mathrm{IR}, \alpha \mathrm{IRS}-1$ and $\alpha$ Shc and bands corresponding to IR $\beta$ (95 kDa), IRS-1 (185 kDa) and Shc (52 kDa) were detected by ECL. Scanning densitometry of autoradiograms was performed on four fasted and refed chickens of each group (control and corticosterone-treated). The data are means \pm S.E.M., $n=4 .{ }^{*} P<0 \cdot 05$. 
A

IP : $\alpha$ PY20

Blot : $\alpha$ IR

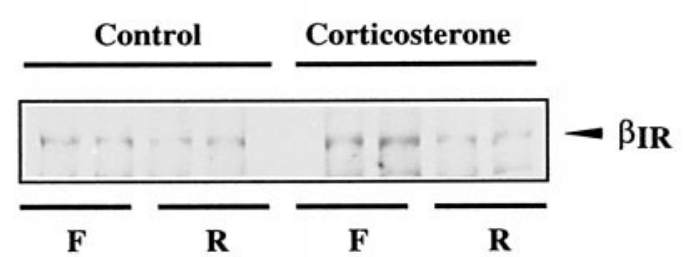

B

IP : $\alpha$ PY20

Blot : $\alpha$ IRS-1

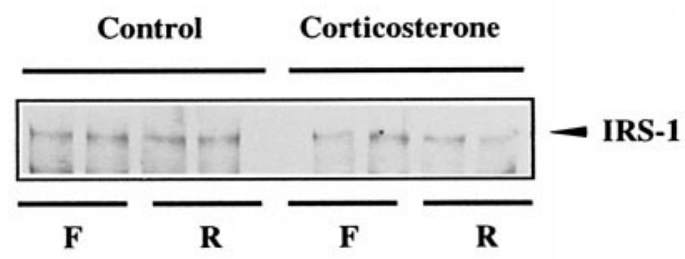

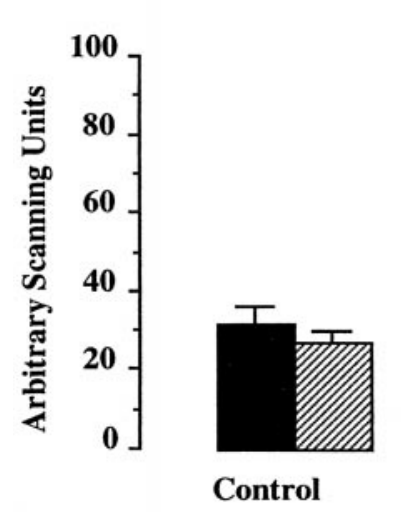
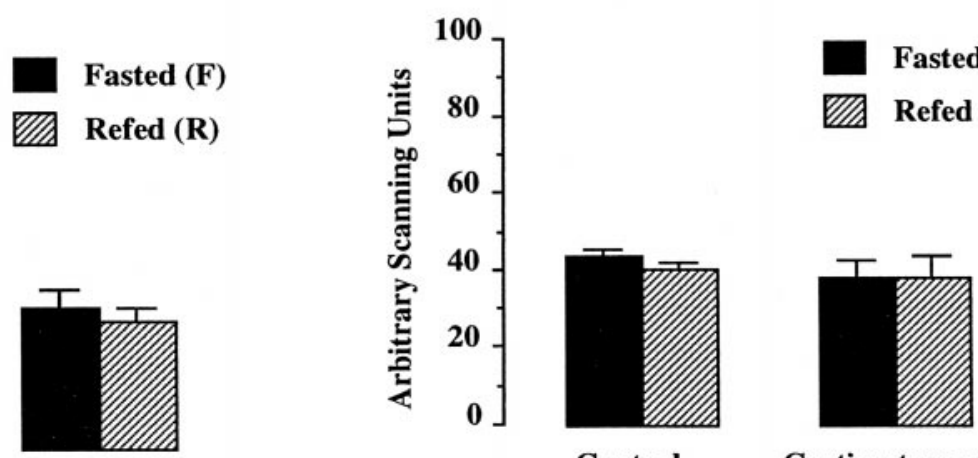

Control

Corticosterone

C

IP : $\alpha$ PY20

Blot : $\alpha$ She
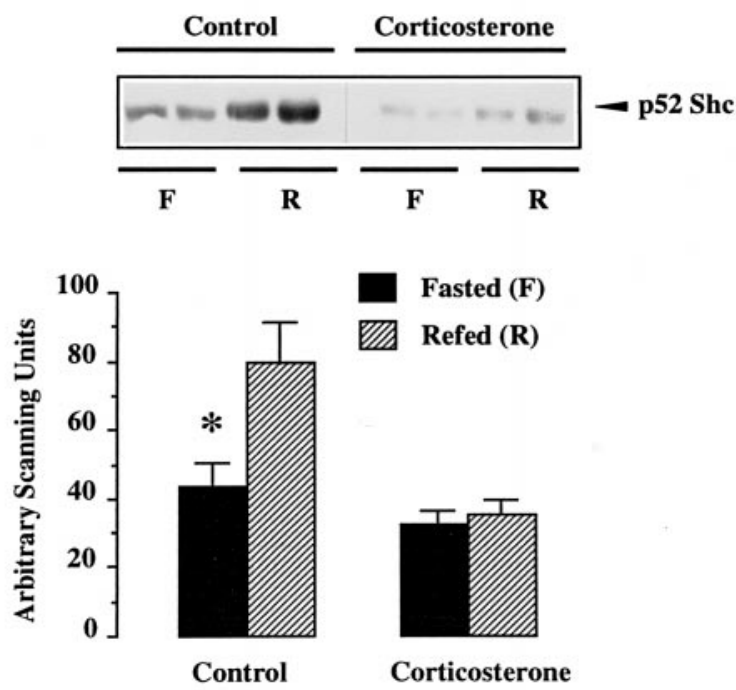

Figure 5 IR $\beta$-subunit (A), IRS-1 (B) and Shc (C) tyrosine phosphorylation in leg muscle of control and corticosterone-treated chickens in fasted and refed states. Solubilized proteins $(5 \mathrm{mg}$ ) were immunoprecipitated using $\alpha$ PY20. Immunoprecipitates were resolved on $10 \%$ SDS-PAGE followed by electroblotting. Blots were successively probed with $\alpha$ IR, $\alpha$ IRS- 1 and $\alpha$ Shc and bands corresponding to IR $\beta$ (95 kDa), IRS-1 (185 kDa) and Shc (52 kDa) were detected by ECL. Scanning densitometry of autoradiograms was performed on four fasted and refed chickens of each group (control and corticosterone-treated). The data are means \pm S.E.M. ${ }^{\star} P<0 \cdot 05$. 
$\mathbf{A}$

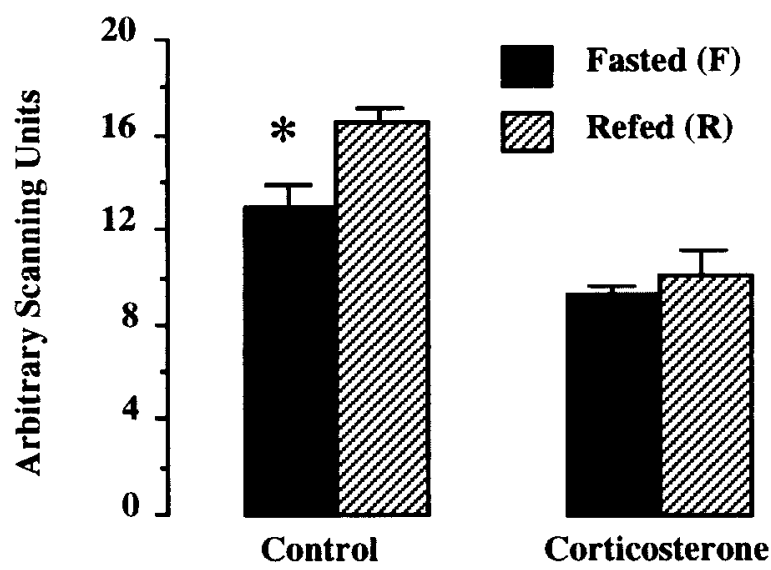

B

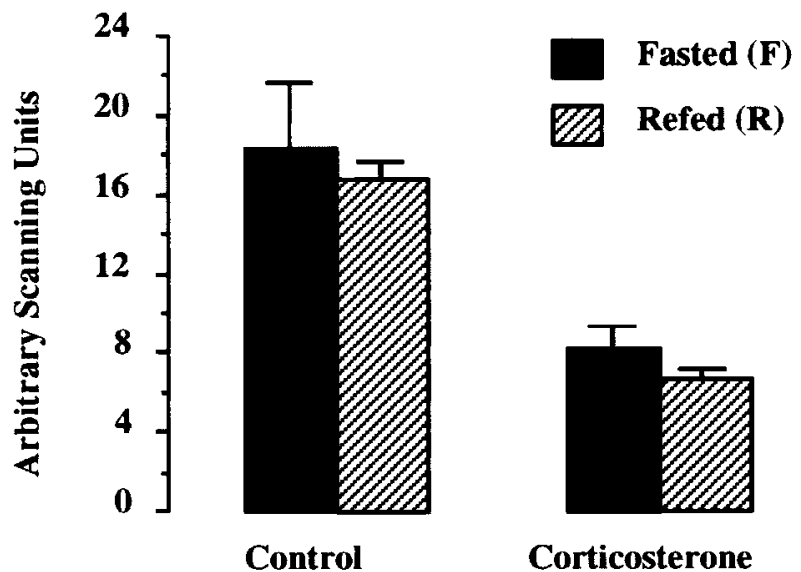

Figure 6 Phosphatidyl inositol 3 phosphate (PI 3')-kinase activity associated with IR in liver (A) and muscle (B) of control and corticosterone-treated chickens in the fasted and refed states. Proteins were extracted and solubilized as described in Materials and Methods and immunoprecipitated with $\alpha$ IR. PI 3'-kinase in the washed immunoprecipitates was assayed as described in Materials and Methods. The resulting labeled lipids were extracted, separated on TLC plates, and visualized by autoradiography. $\left[{ }^{33} \mathrm{P}\right]$ phosphate incorporated into PI(3)P was quantified using phosphoimager (Molecular Dynamics) and is reported as arbitrary units. Values are means \pm S.E.M. of four chickens of each group, ${ }^{*} P<0 \cdot 05$.

In muscle, in the basal state, the amount of tyrosine phosphorylated IRS-1 and Shc was not altered, despite the decrease in IRS-1 protein and messenger levels following corticosterone treatment. In control as well as in treated chickens, refeeding did not stimulate the phosphorylation of IRS-1 which fits with previous observations concerning IR phosphorylation. In control chickens, the phosphoryl- ation of Shc was stimulated by refeeding and this response was inhibited by corticosterone. These results further emphasize the peculiarities found in chicken muscle for insulin signaling. Therefore, it is difficult to identify what mechanism accounts for the large impairment of muscle development in the chicken after corticosterone treatment.

Corticosterone also affected IR-associated PI 3'-kinase activity in liver and muscle. In liver, basal PI $3^{\prime}$-kinase activity (as measured in the fasted state) was significantly reduced in corticosterone-treated chickens. This may be the consequence of the alteration of $\mathrm{p} 85$ levels (protein and mRNA). However, refeeding enhanced liver PI 3'-kinase activity in control but not in corticosterone-treated chickens. This is most probably the consequence of reduced tyrosine phosphorylation of IR, IRS-1 and Shc. Recently, we demonstrated that, at least in chicken liver, PI $3^{\prime}$ kinase was involved in a multimeric complex including IR, IRS-1 and Shc (mainly the $52 \mathrm{kDa}$ isoform, Dupont et al. 1998b). Therefore, any alteration in the level of tyrosine phosphorylation of these molecules potentially affects the association/activation of PI 3'-kinase. This type of complex has not been demonstrated in mammals and may be one of the peculiarities of insulin signaling in the chicken. In muscle, the amount of p 85 subunit and the basal PI 3'-kinase activity were low after corticosterone treatment, which may contribute to a poor control of muscle metabolism and the impairment of muscle growth. However, the lack of activation of this enzyme in control and treated chickens after refeeding leads us to question the role of this enzyme in the control of muscle metabolism by insulin in this species.

In conclusion, insulin resistance and growth and metabolic perturbations induced by corticosterone are associated with several changes along the insulin signaling cascade which are likely to be of physiological importance for the development of insulin resistance. In liver, the amount of IR, IRS-1 and p85, the tyrosine phosphorylation of IR, IRS-1 and Shc, and the activation of PI $3^{\prime}$-kinase are decreased by corticoids. In muscle, corticosterone also induced several alterations. However, the present results provide further evidence for the presence of an apparent insulin insensitivity of insulin signaling pathways in chicken muscle. The consequences for chicken muscle physiology remain to be investigated.

\section{Acknowledgement}

This work was financially supported by a grant from AFM (Association Française contre les Myopathies).

\section{References}

Adamo M, Simon J, Rosebrough RW, McMurtry JP, Steele NC \& LeRoith D 1987 Characterization of the chicken muscle insulin receptor. General and Comparative Endocrinology 68 456-465. 
Amatruda JM, Livingston JN \& Lockwood DH 1985 Cellular mechanisms in selected states of insulin resistance: human obesity, glucocorticoid excess and chronic renal failure. Diabetes/Metabolism Reviews 3 293-317.

Baxter J \& Forshman P 1972 Tissue effects of glucocorticoids. American Journal of Medicine $\mathbf{5 3}$ 573-577.

Cahill GF Jr 1971 Action of adrenal cortex steroids on carbohydrate metabolism. In The Human Adrenal Cortex, pp 205-238. Ed. NP Chisty. New York: Harper and Row.

Case RD, Piccione E, Wolf G, Benett AM, Lechleider RJ, Neel BG \& Shoelson SE 1994 SH-PTP2 syp SH2 domain binding specificity is defined by direct interactions with platelet-derived growth factor $\beta$-receptor, epidermal growth factor receptor, and insulin receptor substrate-1 derived phosphopeptides. Journal of Biological Chemistry 269 10467-10474.

Dupont J, Derouet M, Simon J \& Taouis M 1998a Nutritional state regulates insulin receptor and IRS-1 phosphorylation and expression in chicken. American Journal of Physiology 274 E309-E316.

Dupont J, Derouet M, Simon J \& Taouis M $1998 b$ Effect of nutritional state on the formation of a complex involving insulin receptor, IRS-1, the $52 \mathrm{kDa}$ Shc isoform and PI 3'-kinase activity. Biochemical Journal 335 293-300.

Exton JH, Miller TB, Harper SC \& Park CR 1976 Carbohydrate metabolism in perfused livers of adrenalectomized and steroidreplaced rats. American Journal of Physiology 230 163-170.

Folli F, Saad MJ \& Kahn CR 1996 Insulin receptor/IRS-1/PI 3-kinase signaling system in corticosteroid-induced insulin resistance. Acta Diabetologia 33 185-192.

Giorgino F, Almahfouz A, Goodyear LJ \& Smith RJ 1993 Glucocorticoid regulation of insulin receptor and substrate IRS-1 tyrosine phosphorylation in rat skeletal muscle in vivo. Journal of Clinical Investigation 91 2020-2030.

Lavan BE, Fantin VR, Chang ET, Lane WS, Keller SR \& Lienhard GE 1997a A novel 160-kDa phosphotyrosine protein in insulintreated embryonic kidney cells is a new member of the insulin receptor substrate family. Journal of Biological Chemistry $\mathbf{2 7 2}$ 21403-21407.

Lavan BE, Lane WS \& Lienhard GE $1997 b$ The 60 kDa phosphotyrosine protein in insulin-treated adipocytes is a new member of the insulin receptor substrate family. Journal of Biological Chemistry 272 11439-11443.

Levy-Toledano R, Caro LHP, Accili D \& Taylor SI 1994 Investigation of the mechanism of the dominant negative effect of mutations in the tyrosine kinase domain of the insulin receptor. EMBO Journal 13 835-842.

Migliaccio E, Mele S, Pelicci SG, Lai KM, Superti-Furga G, Pawson T, Di Fiore PP, Lanfrancone L \& Pelicci PG 1997 Opposite effects of the p52 shc/p46 shc and p66 shc splicing isoforms on the EGF receptor-MAP kinase-fos signalling pathway. EMBO Journal $16706-716$
Myers MG, Wang L, Sun XJ, Zhang Y, Yenush L, Schlessinger J, Pierce JH \& White MF 1994 Role of IRS-1-Grb2 complexes in insulin signaling. Molecular and Cellular Biology 14 3577-3587.

Olefsky JM 1975 Effect of dexamethasone on insulin binding, glucose transport and glucose oxidation of isolated rat adipocytes. Journal of Clinical Investigation 56 1499-1508.

Patti ME, Sun XJ, Bruening JC, Araki E, Lipes MA, White MF \& Kahn CR 1995 4PS/insulin receptor substrate (IRS)-2 is the alternative substrate of the insulin receptor in IRS-1-deficient mice. Journal of Biological Chemistry 270 24670-24673.

Pelicci G, Lanfrancone L, Grignani F, McGlade J, Cavallo F, Forni G, Nicoletti I, Grignani F, Pawson T \& Pelicci PG 1992 A novel transforming protein (SHC) with an $\mathrm{SH} 2$ domain is implicated in mitogenic signal transduction. Cell 70 93-104.

Saad MJA, Folli F, Kahn JA \& Kahn CR 1993 Modulation of insulin receptor, insulin receptor substrate-1 (IRS-1) and phosphatidylinositol 3-kinase in liver and muscle of dexamethasone treated rats. Journal of Clinical Investigation 92 2065-2072.

Saltiel AR 1996 Diverse signaling pathways in the cellular actions of insulin. American Journal of Physiology 270 E375-E385.

Sanchez-Margelet V, Goldfine JD, Truitt K, Imboden J \& Sung CJ 1995 Role of $\mathrm{p} 85$ subunit of phosphatidylinositol-3 kinase as an adaptor molecule linking the insulin receptor to insulin receptor substrate 1. Molecular Endocrinology 9 435-442.

Sasaoka T, Draznin B, Leitner JW, Langlois WJ \& Olefsky JM 1994 Shc is the predominant signaling molecule coupling insulin receptors to activation of guanine nucleotide releasing factor and p21ras-GTP formation. Journal of Biological Chemistry 269 10734-10738.

Sun XJ, Rothenberg JP, Kahn CR, Backer JM, Araki E, Wilden PA, Cahill DA, Goldstein BJ \& White MF 1991 Structure of the insulin receptor substrate IRS-1 defines a unique signal transduction protein. Nature 352 73-77.

Taouis M, Derouet M, Chevalier B \& Simon J 1993 Corticosterone effect on insulin receptor number and kinase activity in chicken muscle and liver. General and Comparative Endocrinology 89 167-175.

Taouis M, Levy-Toledano R, Roach P, Taylor SI \& Gorden P 1994 Structural basis by which a recessive mutation in the $\alpha$-subunit of the insulin receptor affects insulin binding. Journal of Biological Chemistry 269 14912-14918.

Taouis M, Taylor SI \& Reitman M 1996 Cloning of the chicken insulin receptor substrate-1 gene. Gene 178 51-55.

White MF \& Kahn CR 1994 The insulin signaling system. Journal of Biological Chemistry 269 1-4.

Received 14 December 1998

Accepted 22 February 1999 